\title{
Sleep quality in stable chronic obstructive pulmonary disease patients in Zagazig University Hospitals, Egypt
}

\author{
Adel H. A. Ghoneim', Mohamed S. El-Gammal', Yasmeen R. Ahmed² and Doaa M. Gad ${ }^{1 *}$
}

\begin{abstract}
Background: Chronic obstructive pulmonary disease (COPD) causes changes in sleep quality with accompanied nocturnal drops in oxygen saturation leading to cardiac dysrhythmias, pulmonary hypertension, and more arousal. However, this sleep disturbance is an aspect of COPD that is still under evaluation. Therefore, this work is designed to detect sleep quality with type and frequency of sleep-related breathing disorders in stable COPD patients.

Results: This is a cross-sectional study that included 60 stable COPD patients. Full night polysomnographies were performed to all patients with assessment of their sleep quality and presence of sleep-disordered breathing. The studied patients were classified into two groups: group I (COPD with good sleep quality) and group II (COPD with poor sleep quality). The results revealed that the more severe the COPD degree, the worse the sleep quality parameters represented by sleep latency, sleep efficiency, and arousal index with a significant statistical difference $(P<0.05)$. Furthermore, a highly significant statistical difference was noticed regarding time spent in REM sleep among poor sleep quality patients with different grades of severity $(P=0.003)$. Additionally, obstructive sleep apnea hypopnea syndrome was the most frequent sleep-disordered breathing (65\%), followed by nocturnal oxygen desaturation (17\%) among poor quality sleeper.

Conclusion: Abnormal sleep quality is more common in moderate and severe COPD patients. Obstructive sleep apnea is the most frequent sleep-related breathing disorders among COPD patients. Increased BMI\%, higher Berlin scores, and lower values of $\mathrm{PaO}_{2}$ and FOSQ-10 scores are strong predictors of poor sleep quality among COPD patients.
\end{abstract}

Keywords: Chronic obstructive pulmonary disease (COPD), Obstructive sleep apnea hypopnea syndrome (OSAHS), Sleep quality

\section{Background}

Chronic obstructive pulmonary disease (COPD) is a serious global health problem [1]. Different studies proposed that more than $75 \%$ of patients with COPD may have nocturnal symptoms and sleep disturbances in the form of prolonged sleep latency, arousals, and frequent insomnias [2], resulting in decrease in patient's activity during daytime associated with more severe disease and frequent exacerbations [3].

\footnotetext{
* Correspondence: dooagad@yahoo.com

${ }^{1}$ Chest Department, Faculty of Medicine, Zagazig University, Zagazig, Egypt Full list of author information is available at the end of the article
}

In COPD, the pathogenesis of sleep disorders appears to be a complex and multifactorial process, which may be a consequence of one or more of the following: physiological changes associated with sleep, disturbance in gas exchanges, and/or COPD medications [4].

Obstructive sleep apnea hypopnea syndrome (OSAHS) is considered a serious disorder represented by repeated nocturnal events of partial or complete cessation of breathing [5].

Patients with both OSA and COPD are considered to have the overlap syndrome (OVS) [6]. Both are associated with similar common pathophysiology, such as
Springer Open (c) The Author(s). 2021 Open Access This article is licensed under a Creative Commons Attribution 4.0 International License, which permits use, sharing, adaptation, distribution and reproduction in any medium or format, as long as you give appropriate credit to the original author(s) and the source, provide a link to the Creative Commons licence, and indicate if changes were made. The images or other third party material in this article are included in the article's Creative Commons licence, unless indicated otherwise in a credit line to the material. If material is not included in the article's Creative Commons licence and your intended use is not permitted by statutory regulation or exceeds the permitted use, you will need to obtain permission directly from the copyright holder. To view a copy of this licence, visit http://creativecommons.org/licenses/by/4.0/. 
hypoxia and systemic inflammation, that contribute to cardiovascular and other comorbidities, particularly pulmonary hypertension which is highly prevalent in those patients [7]. OVS had more profound nocturnal and daytime hypoxemia and hypercapnia than patients with COPD or OSA alone [8]. Moreover, both were associated with poor outcome, including high mortality [6]. Unfortunately, sleep-disordered breathing symptoms are an aspect of COPD that is considerably neglected by many physicians leading to negative impact on treatment efforts for COPD patients [2].

Therefore, this work is designed to detect sleep quality with type and frequency of sleep-related breathing disorders in stable COPD patients.

\section{Methods}

\section{Study design and setting}

This cross-sectional study was carried out at a SleepDisordered Breathing unit (SDB) of Chest Department and Out-patient Clinic, Zagazig University Hospitals, during the period from February till August 2016.

\section{Patients}

This study included 60 stable chronic obstructive pulmonary disease patients with different degrees of severity as assessed by spirometry according to GOLD [9]. They were 42 males and 18 females with mean age of $58.46 \pm$ 7.87 years.

All patients fulfilling the criteria of stable COPD with different degrees of severity were included [9], while the following conditions were excluded: COPD in exacerbations [9], or under mechanical ventilation or receiving non-invasive positive pressure ventilation, obstructive airway diseases rather than COPD, e.g., asthma or bronchiectasis. COPD patients with uncontrolled hypertension, unstable angina, uncontrolled diabetes, neuromuscular disease, cerebrovascular accident (CVA), left-sided heart failure, chronic renal failure, chronic liver cell failure, thyrotoxicosis, malignancy, psychiatric diseases, addiction and alcohol intake, or obesity hypoventilation syndrome were excluded. This research was approved by the Ethics
Committee of Zagazig Faculty of Medicine. An informed written consent was collected from all participants.

\section{Methods}

All patients were subjected to the following:

1. Full meticulous medical history taking stressing on: associated comorbidities, history of drug intake and special habits (e.g., smoking, alcohol intake), and sleep-disordered breathing symptoms that were assessed by the following: Epworth sleepiness scale (ESS) questionnaire [10], Berlin questionnaire [11], and functional outcome of sleep questionnaire (FOSQ-10 short version) [12].

2. General and local chest examination, stressing on recording neck circumference, waist circumference, and body mass index (BMI) (weight in $\mathrm{kg} /$ height $\left.\mathrm{m}^{2}\right)$ [13].

3. Plain chest $\mathrm{x}$-ray (postero-anterior and lateral views).

4. Pulmonary function tests (PFT)

5. Laboratory investigations: complete blood count $(\mathrm{CBC})$, liver function tests (LFTs), kidney function tests (KFTs), random blood sugar (RBS), thyroid function tests (TSH, Free T3, and Free T4), and arterial blood gas analysis (ABGs): after awaking and during day time.

6. Electrocardiography (ECG).

7. COPD assessment test (CAT) [14] and the modified Medical Research Council (mMRC) dyspnea scale for assessment of dyspnea level [9].

8. Full-night polysomnographic sleep study (PSG): It was done using SOMNO screen ${ }^{\text {Th }}$ plus (Germany) to all patients.

A. The following respiratory disorders were reviewed:

- Apneas and hypopneas with recording the presence of obstructive, central, or mixed events.

Table 1 Demographic data of the studied patients

\begin{tabular}{|c|c|c|c|c|}
\hline & & $\begin{array}{l}\text { Group I COPD patients with } \\
\text { good sleep quality }(n=20)\end{array}$ & $\begin{array}{l}\text { Group II COPD patients with } \\
\text { poor sleep quality }(n=40)\end{array}$ & Test of significance \\
\hline \multirow{2}{*}{\multicolumn{2}{|c|}{ Age (years) (mean $\pm S D$ ) }} & $56.85 \pm 7.13$ & $59.27 \pm 8.18$ & $t=-1.12$ \\
\hline & & & & $P=0.264$ \\
\hline \multirow[t]{2}{*}{ Sex } & Male No. (\%) & $11(55 \%)$ & $31(77.5 \%)$ & $x^{2}=3.21$ \\
\hline & Female No. (\%) & $9(45 \%)$ & $9(22.5)$ & $P=0.073$ \\
\hline \multirow[t]{2}{*}{ Smoking } & Smoker No (\%) & $8(40 \%)$ & $28(70 \%)$ & $x^{2}=7.81$ \\
\hline & Non-smoker No (\%) & $12(60 \%)$ & $12(30 \%)$ & $P=0.005$ \\
\hline
\end{tabular}

$\mathrm{S}=P$ value $<0.05$ 
Table 2 Comparison between both groups regarding total sleep time, sleep latency, sleep efficiency, and arousal index

\begin{tabular}{|c|c|c|c|}
\hline & $\begin{array}{l}\text { Group I COPD patients with } \\
\text { good sleep quality }(n=20)\end{array}$ & $\begin{array}{l}\text { Group II COPD patients with } \\
\text { poor sleep quality }(n=40)\end{array}$ & Test of significance \\
\hline Total sleep time (min) (mean \pm SD) & $370.50 \pm 39.6$ & $269.32 \pm 26.56$ & $\begin{array}{l}t=11.75^{a} \\
P=0.00\end{array}$ \\
\hline Sleep latency (min) (mean \pm SD) & $27.35 \pm 2.8$ & $32.92 \pm 16.89$ & $\begin{array}{l}z=3.02^{b} \\
P=0.004\end{array}$ \\
\hline Sleep efficiency (\%) (mean \pm SD) & $89.55 \pm 2.58$ & $61.6 \pm 6.76$ & $\begin{array}{l}t=17.77^{\mathrm{a}} \\
P=0.00\end{array}$ \\
\hline Arousal index (No/h) (mean $\pm \mathrm{SD})$ & $4.385 \pm 2.1$ & $18.73 \pm 6.15$ & $\begin{array}{l}z=-9.7^{b} \\
P=0.00\end{array}$ \\
\hline
\end{tabular}

${ }^{a}$ Student $t$ test

${ }^{\mathrm{b}}$ Mann-Whitney test were used

$\mathrm{HS}=P$ value $<0.001, \mathrm{~S}=P$ value $<0.05$

- Apnea hypopnea index (AHI) which is classified as follows: normal (AHI < 5), mild sleep apnea (AHI 5-14), moderate sleep apnea (AHI 15-29), and severe sleep apnea (AHI $\geq 30)$ [15].

- Respiratory effort-related arousal (RERA), respiratory disturbance index (RDI), and arousals

- Cheyne-Stokes breathing

B. Detecting oxygen desaturation index (sum of all desaturations, minimal and baseline oxygen saturation)

C. Snoring Index

D. Assessment of sleep quality according to the following parameters: sleep latency, duration, efficiency, fragmentation, and the hypnogram. Accordingly, good sleep quality is defined as: sufficient duration $>7 \mathrm{~h} /$ night, high sleep efficiency $>85 \%$, low sleep fragmentation $<25$, and normal hypnogram [16].

\section{Statistical analysis}

Data were imported into the Statistical Package for the Social Sciences (SPSS version 20.0) software for analysis. According to the type of data, qualitative was presented as number and percentage and quantitative continuous group was presented by mean $\pm \mathrm{SD}$; the following tests were used to test differences for significance. Differences between frequencies (qualitative variables) and percentages in groups were compared by Chi-square test. Differences between parametric quantitative independent groups were compared by $t$ test, while differences between non-parametric data were compared by MannWhitney test, however multiple parametric groups were compared by ANOVA test, and multiple nonparametric groups were compared by KruskalWallis test. Correlation between groups was carried out by Pearson's correlation. The results were considered significant if $P$ value $<0.05$ was detected.

\section{Results}

This study included 60 stable COPD patients with different grades of severity. All patients underwent PSG study. According to their sleep quality, they were classified into two groups: group I )20 COPD patients with good sleep quality) and group II (40 COPD patients with poor sleep quality). Both studied groups were matched regarding age and sex with non-significant statistical difference $(P>0.05)$. However, there is a highly significant statistical increase in smoking habit in poor sleep quality group II than those of group I $(P<0.01)$ (Table 1$)$.

Table 3 Sleep parameters among poor sleep quality COPD patients with different grades of severity

\begin{tabular}{|c|c|c|c|c|c|}
\hline \multirow[t]{2}{*}{ Sleep parameters } & \multicolumn{5}{|c|}{ Poor sleep quality COPD patients $(n=40)$} \\
\hline & Mild $(N=4)$ & Moderate $(N=18)$ & Severe $(N=14)$ & Very severe $(N=4)$ & Test of significance $^{\mathrm{a}}$ \\
\hline Total sleep time $(\mathrm{min})($ mean $\pm \mathrm{SD})$ & $287.2 \pm 18.8$ & $274.8 \pm 14.9$ & $263.7 \pm 32.3$ & $246.0 \pm 39.2$ & $\begin{array}{l}F=2.31 \\
P=0.09\end{array}$ \\
\hline Sleep latency (min) (mean \pm SD) & $9.2 \pm 2.9$ & $10.1 \pm 6.8$ & $10.5 \pm 5.3$ & $27 \pm 4.9$ & $\begin{array}{l}F=11.01 \\
P=0.009\end{array}$ \\
\hline Sleep efficiency (\%) (mean \pm SD) & $73 \pm 1.6$ & $65 \pm 3.8$ & $56 \pm 2.3$ & $53 \pm 3.3$ & $\begin{array}{l}F=46.7 \\
P=0.007\end{array}$ \\
\hline Arousal index (No/h) (mean $\pm \mathrm{SD})$ & $11.7 \pm 4.2$ & $15.8 \pm 4.3$ & $21.8 \pm 3.8$ & $28 \pm 6.1$ & $\begin{array}{l}F=15.12 \\
P=0.02\end{array}$ \\
\hline
\end{tabular}

${ }^{\mathrm{a} F}$ ANOVA test

$S=P$ value $<0.05$ 
Table 4 Sleep stages among poor sleep quality COPD patients with different grades of severity

\begin{tabular}{|c|c|c|c|c|c|c|}
\hline \multicolumn{2}{|c|}{ Sleep stages } & \multicolumn{5}{|c|}{ Poor sleep quality COPD patients $(n=40)$} \\
\hline & & \multirow{2}{*}{$\begin{array}{l}\text { Mild }(n=4) \\
78.7 \pm 25.5\end{array}$} & \multirow{2}{*}{$\begin{array}{l}\text { Moderate }(\boldsymbol{n}=\mathbf{1 8}) \\
87.3 \pm 23.8\end{array}$} & \multirow{2}{*}{$\begin{array}{l}\text { Severe }(n=14) \\
94.8 \pm 29.01\end{array}$} & \multirow{2}{*}{$\begin{array}{l}\text { Very severe }(\boldsymbol{n}=\mathbf{4}) \\
70.0 \pm 46.9\end{array}$} & \multirow{2}{*}{$\begin{array}{l}\text { Test of significance } \\
F=0.88 \\
P=0.41\end{array}$} \\
\hline N1 & Min $($ mean \pm SD) & & & & & \\
\hline & $\%$ of TIB (mean \pm SD) & $16.50 \pm 6.24$ & $18.11 \pm 5.83$ & $19.92 \pm 6.00$ & $14.75 \pm 10.66$ & $\begin{array}{l}F=0.80 \\
P=0.49\end{array}$ \\
\hline \multirow[t]{2}{*}{ N2 } & Min (mean \pm SD) & $137.5 \pm 17.09$ & $118.6 \pm 38.5$ & $133.3 \pm 21.2$ & $147.0 \pm 62.8$ & $\begin{array}{l}F=1.42 \\
P=0.37\end{array}$ \\
\hline & $\%$ of TIB (mean $\pm \mathrm{SD})$ & $28.75 \pm 3.77$ & $24.83 \pm 8.48$ & $27.64 \pm 4.60$ & $30.75 \pm 16.85$ & $\begin{array}{l}F=0.78 \\
P=0.51\end{array}$ \\
\hline \multirow[t]{2}{*}{ N3 } & Min $($ mean $\pm S D)$ & $43.0 \pm 15.6$ & $43.6 \pm 17.9$ & $28.2 \pm 19.8$ & $21.0 \pm 42.6$ & $\begin{array}{l}F=1.19 \\
P=0.31\end{array}$ \\
\hline & $\%$ of TIB $($ mean $\pm \mathrm{SD})$ & $9.00 \pm 4.24$ & $8.50 \pm 4.68$ & $5.71 \pm 4.77$ & $4.50 \pm 9.00$ & $\begin{array}{l}F=1.28 \\
P=0.29\end{array}$ \\
\hline \multirow[t]{2}{*}{ REM } & Min $($ mean $\pm S D)$ & $28.0 \pm 9.2$ & $25.21 \pm 20.4$ & $7.3 \pm 6.9$ & $7.2 \pm 15.0$ & $\begin{array}{l}F=3.92 \\
P=0.003\end{array}$ \\
\hline & $\%$ of TIB (mean $\pm \mathrm{SD})$ & $5.75 \pm 1.70$ & $5.16 \pm 5.57$ & $1.46 \pm 1.57$ & $1.50 \pm 3.00$ & $\begin{array}{l}F=2.89 \\
P=0.04\end{array}$ \\
\hline
\end{tabular}

TIB time in bed, REM Rapid eye movement, F ANOVA test

$\mathrm{S}=P$ value $<0.05$

Table 2 shows that COPD patients with poor sleep quality had a lower total sleep time and sleep efficiency $(P=0.00)$, but a more prolonged sleep latency $(P=$ $0.004)$ and a higher arousal index $(P=0.00)$ when compared to COPD patients with good sleep quality.

Table 3 illustrates that among poor sleep quality COPD patients, the more severe the COPD degree, the worse the sleep quality parameters including sleep latency $(P=0.009)$, sleep efficiency $(P=0.007)$, and arousal index $(P=0.02)$, but not the total sleep time $(P=0.09)$.

Table 4 shows that the more the severity of COPD, the less the time spent in REM sleep $(p=0.003)$ among patients with poor sleep quality.

Various types of sleep-disordered breathing were observed among COPD patients with poor sleep quality in which OSAHS is the most frequent sleep-disordered breathing (65\%), followed by nocturnal oxygen desaturation (17\%) (Table 5).

Our results revealed a significant positive correlation between sleep efficiency and $\mathrm{FEV}_{1}$, accompanied with highly significant negative correlation between sleep efficiency and BMI and a significant negative correlation between sleep efficiency and mMRC dyspnea scale

Table 5 Sleep-related breathing disorders in COPD patients with poor sleep quality

\begin{tabular}{lll}
\hline COPD patients with poor sleep quality $(\boldsymbol{n}=\mathbf{4 0})$ & No. & \% \\
\hline Obstructive sleep apnea hypopnea syndrome (OSAHS) & 26 & $65 \%$ \\
Central sleep apnea hypopnea syndrome (CSAHS) & 2 & $5 \%$ \\
Nocturnal hypoventilation & 5 & $13 \%$ \\
Nocturnal oxygen desaturation & 7 & $17 \%$ \\
\hline
\end{tabular}

(Figs. 1, 2, and 3) with $P$ value $<0.01,<0.001$, and $<$ 0.05 respectively, as seen in Table 6 .

Table 7 shows multiple regression analysis used to assess predictors of poor sleep quality in COPD patients. It isolates four significant independent predictors: increased BMI and Berlin score, decrease in $\downarrow \mathrm{PaO}_{2}$ and $\downarrow$ FOSQ-10 score $(P=0.04, P=0.008, P=0.01, P=0.000)$ respectively. Values were estimated in logistic regression by ROC curve as $\mathrm{PH}<7.39$, Epworth $\mathrm{SS}>9.8$, FOSQ-10 $\mathrm{Q}<13.2$, Berlin $\mathrm{Q}>1$, $\mathrm{BMI}>26.5, \mathrm{PaO}_{2}<86.2, \mathrm{PaCO}_{2}$ $>45.5$ and $\mathrm{FEV}_{1}<80 \%$ according to GOLD [9].

\section{Discussion}

Chronic obstructive pulmonary disease (COPD) patients are at risk of insomnia and difficulty in initiating and maintaining sleep. This sleep fragmentation and poor sleep quality had an important impact on their quality of life and health outcome measures [17]. Therefore, this work was designed to detect the frequency of sleeprelated breathing disorders in COPD patients and its impact on sleep quality in such patients. In this study, stable COPD patients were included and classified into: group I (20 COPD patients with good sleep quality) and group II (40 COPD patients with poor sleep quality) patient.

In the current study, both groups were matched regarding age and sex (Table 1$)$. In contrast to these results, Akerstedt et al. [18] reported that sleep quality was affected by gender difference and age. This may be due to their study being carried out on patients with extremes of age while our study was conducted on elderly patients: their mean age was $58.46 \pm 7.87$ years only. Besides, a significant statistical difference between group I 


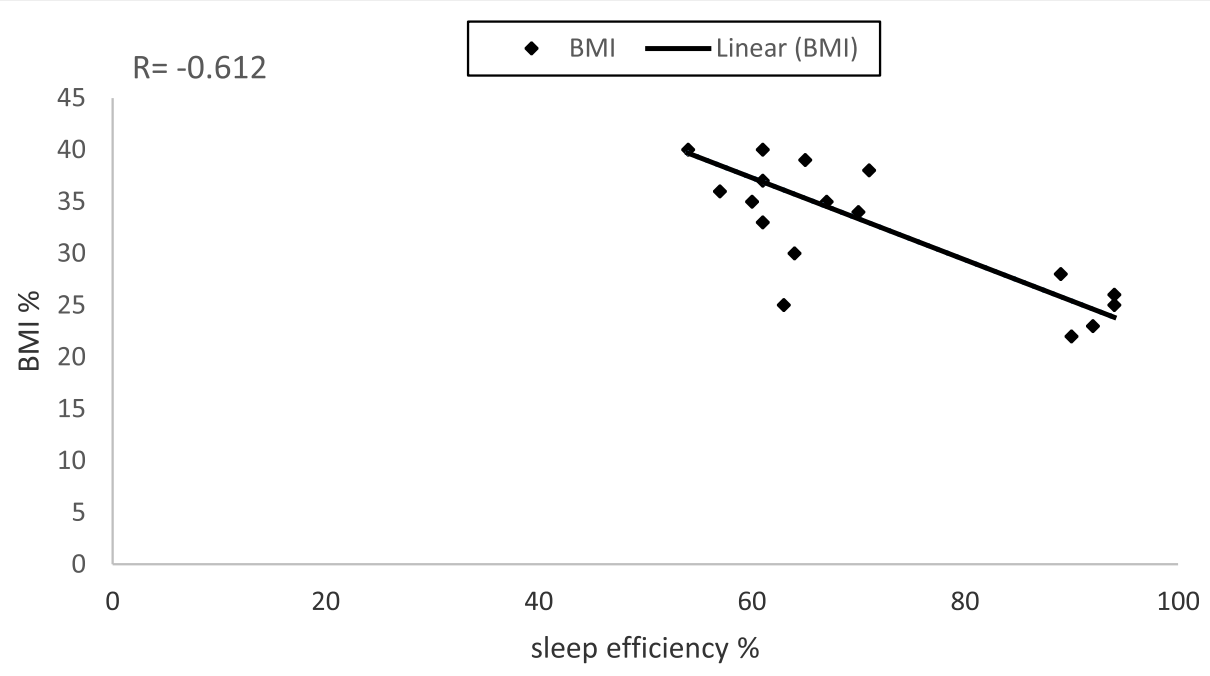

Fig. 1 Correlation between sleep efficiency and BMI among studied COPD patients

and group II was observed as regard smoking habit. These results signified that there were other factors that add further burden on sleep quality like smoking as a special habit independent from the pathophysiology of the COPD itself. Cohrs et al. [19] and Liao et al. [20] strongly supported that smoking negatively affect sleep. Preliminary data suggested that cigarette smoking was associated with poor sleep quality in the form of impairment in subjective sleep quality, sleep latency, sleep duration, and habitual sleep efficiency, with frequent sleep disturbances. Moreover the physiological desire for additional nicotine during sleep may cause smokers to awaken, leading to insomnia. Furthermore, nicotine causes the release of nitric oxide which relaxes the pharyngeal smooth muscles and reduces muscular tone and activity [21] with increasing the risk for snoring and obstructive sleep [20].

Regarding sleep parameters (Table 2), our results were in harmony with Mcsharry et al. [17] who concluded an impaired sleep quality among COPD patients with total sleep time $=272.5 \pm 86.6 \mathrm{~min}$, sleep latency $=36.8 \pm$ $33.9 \mathrm{~min}$, sleep efficiency $=66 \pm 17 \%$, and arousal index $=16.2 \pm 14.1 / \mathrm{h}$ with REM stage $12.7 \pm 8.3 \mathrm{~min}$. Also, Krachman et al. [22] and Azuma et al. [23] reported lower values of sleep efficiency and total sleep time among such patients after performing polysomnographic sleep studies.

Concordantly, Adetiloye et al. [24], who assessed sleep quality in COPD patients after using the Pittsburgh Sleep Quality Index (PSQI), had noticed that the overall

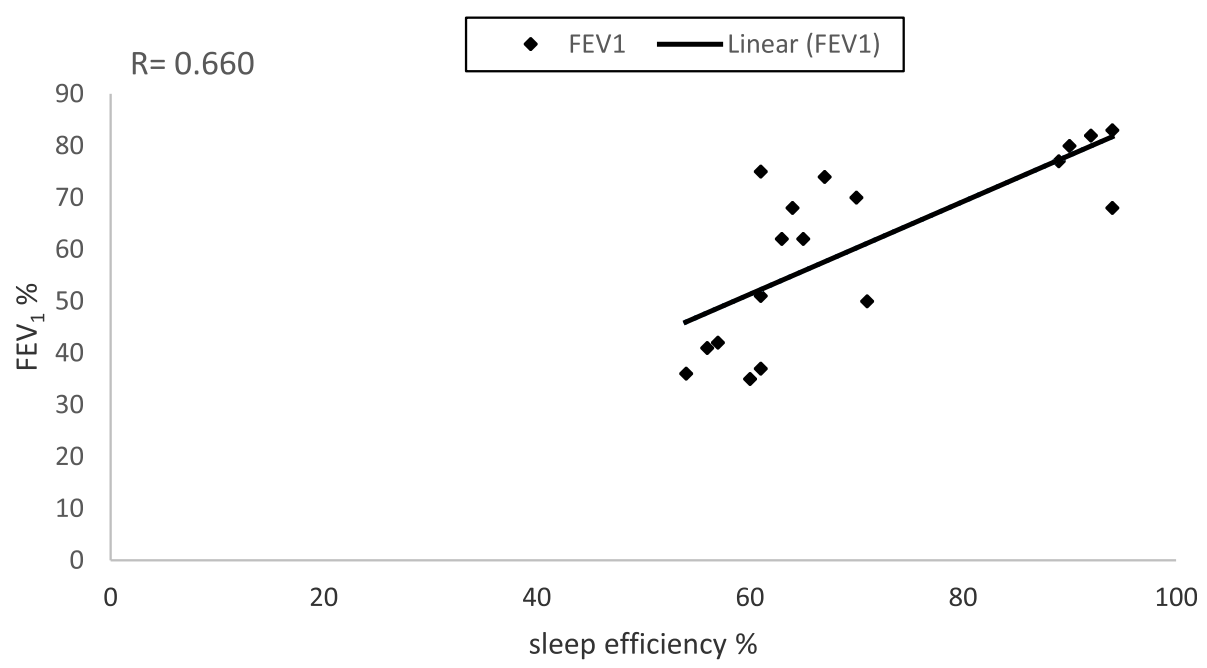

Fig. 2 Correlation between sleep efficiency and FEV 1 among studied COPD patients 


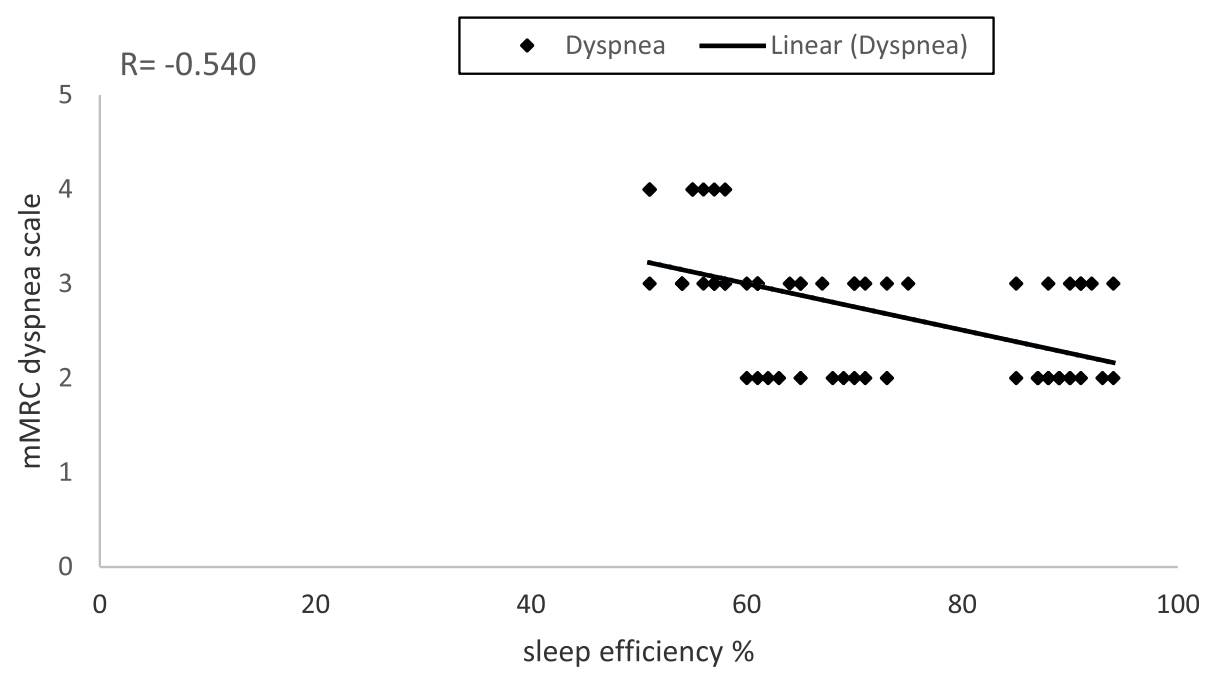

Fig. 3 Correlation between sleep efficiency and mMRC dyspnea scale among studied COPD patients

sleep quality is poor with the median sleep latency was 30 min, 33\% having median total sleep time of less than $5 \mathrm{~h} ; 90 \%$ of the studied patients had $<85 \%$ sleep efficiency, $41.7 \%$ reporting sleep efficiency of $<65 \%$.

This sleep fragmentation is attributed to the aggravating common nocturnal symptoms of cough, dyspnea, chest tightness, or wheezing that are related to COPD. However, lying flat per se impairs pulmonary mechanics and gas exchange resulting in more hypoxemia, which is likely a stronger stimulus for arousals, as it induces neural injury that elicits cortical activation with neurotransmitter-modulated reflex for arousal aiming to correct the situation [24].

In the current study, it was obvious that the more COPD severity, the more worsening of sleep quality (Tables 3 and 4). Similar results were noticed by Chang et al. [25] and Vogelmeier et al .[26], who concluded that COPD patients with more symptoms (group B or group $\mathrm{D} ; \mathrm{mMRC} \geq 2$ or CAT $\geq 10$ ) had a higher percentage of sleep disturbance; its causes are multifactorial, including increase in respiratory symptoms, oxygen desaturation, presence of OSA, psychiatric disorders, and medicationrelated insomnia like oral steroids, inhaled steroids, beta agonists, and theophylline.

Table 6 Correlation between sleep efficiency and BMI, FEV and mMRC dyspnea scale among all studied COPD patients

\begin{tabular}{lll}
\hline & $\boldsymbol{r}$ & $\boldsymbol{P}$ value \\
\hline BMI \% & -0.612 & $<0.001$ \\
FEV $_{1}$ & 0.660 & $<0.01$ \\
mMRC dyspnea scale & -0.540 & $<0.05$ \\
\hline
\end{tabular}

$B M I$ body mass index, $F E V_{1}$ forced expiratory volume at first second, $m M R C$ modified Medical Research Council

$\mathrm{S}=P$ value $<0.05, \mathrm{HS}=P$ value $<0.001$
This signified how COPD and its consequences, comorbidities, and complications affect sleep pattern of these patients. The combination of alveolar hypoventilation and ventilation-perfusion mismatch occurs mostly in the form of severe episodes during REM sleep. Besides, during REM sleep, the diaphragm and intercostal muscle activities were decreased, that proceed to reduced tidal volume and reduced minute ventilation. This progressed into frequent arousals, disturbed REM sleep with decreased sleep time, and more changes in sleep stages [27]. Additionally, Sanders et al. [28] reported that if poor sleep quality was detected with mild COPD patients which is less to occur, there would be an underlying cause for this sleep disturbance rather than COPD itself.

It was obvious from the current results that OSAHS is the most frequent sleep-disordered breathing (65\%), followed by nocturnal oxygen desaturation (17\%) (Table 5). These results were close to that of Abdel Maabood et al. [29] who stated that OSAHS and nocturnal oxygen desaturation were common in COPD patients with prevalence $76 \%$ and $24 \%$ respectively. Also, Povitz et al. [30] and Copur et al. [31] found that the prevalence of OSA in COPD patients in their studies were $69 \%$ and $77 \%$ respectively.

This certify how sleep in chronic obstructive pulmonary disease (COPD) is associated with oxygen desaturation, and the coexistence of COPD and obstructive sleep apnea (overlap syndrome) is very common. Overlap patients have worse sleep-related hypoxemia and hypercapnia than patients with COPD or OSA alone, as oxygen desaturation during sleep is more pronounced when the two conditions coexist. This causes more subjectively and objectively impaired sleep quality [32]. 
Table 7 Logistic regression analysis for predictors of poor sleep quality in COPD patients

\begin{tabular}{|c|c|c|c|c|c|}
\hline Independent factors & Wald & Std. error & Standardized coefficient betas & OR (Cl 95\%) & $P$ value \\
\hline BMI \% > 26.5 & 4.521 & 0.212 & -0.196 & $2.14(1.2-8.52)$ & $0.044^{*}$ \\
\hline Low FEV $1(<80 \%)$ & 1.256 & 0.073 & 0.103 & $1.87(0.85-12.5)$ & 0.282 \\
\hline $\mathrm{PH}<7.39$ & 2.014 & 62.51 & 0.276 & $1.75(0.62-5.62)$ & 0.053 \\
\hline Smoking & 2.142 & 14.25 & 0.054 & $2.85(0.79-11.23)$ & 0.125 \\
\hline $\mathrm{PaO}_{2}<86.2(\mathrm{mmHg})$ & 5.682 & 0.105 & 0.388 & $3.85(1.85-13.2)$ & $0.011^{*}$ \\
\hline $\mathrm{PaCO}_{2}>45.5(\mathrm{mmHg})$ & 0.954 & 0.185 & 0.037 & $2.11(0.92-8.32)$ & 0.711 \\
\hline ESS score $>9.8$ & 0.854 & 0.256 & -0.014 & $3.12(0.64-9.36)$ & 0.868 \\
\hline FOSQ-10 score $<13.2$ & 6.254 & 0.452 & 0.510 & $4.25(2.1-7.58)$ & $0.00^{* *}$ \\
\hline Berlin score $>1$ & 5.897 & 0.195 & -0.394 & $3.01(1.85-13.28)$ & $0.008^{*}$ \\
\hline
\end{tabular}

$\mathrm{BMI}$ body mass index, $\mathrm{FEV}_{1}$ forced expiratory volume at first second, $\mathrm{PaO}_{2}$ partial arterial oxygen pressure, $\mathrm{PaCO} \mathrm{C}_{2}$ partial arterial carbon dioxide pressure, $E S S$ Epworth sleepiness scale, FOSQ functional outcome of sleep questionnaire $\mathrm{S}=P$ value $<0.05, \mathrm{HS}=P$ value $<0.001$

Besides, a significant positive correlation between sleep efficiency and $\mathrm{FEV}_{1}$ were observed, accompanied with highly significant negative correlation between sleep efficiency and BMI and a significant negative correlation between sleep efficiency and mMRC dyspnea scale (Table 6). This signifies that $\mathrm{FEV}_{1}$ and BMI highly contributed in determining sleep quality in COPD patient. Similar results were obtained by Chen et al. [33]. Additionally, In et al. [34] and Abd El-Fattah et al. [35] found negative correlation between PSQI and FEV1\% and FVC. However, Scharf et al. [36] found unremarkable difference regarding the relationship between FEV1\% and sleep quality (PSQI) this controversy may be due to a limited group of their studied patients performed polysomnographic sleep study, so the objective determination of the prevalence of sleep breathing disorders is not presented.

After performing multiple regression analysis to assess predictors of poor sleep quality in COPD patients, it isolated four significant independent predictive parameters: increased BMI and Berlin score, decrease in $\mathrm{PaO}_{2}$ and FOSQ-10 score (Table 7). In agreement with the current results, Krachman et al. [22] noticed that decrease in $\mathrm{PaO}_{2}$ only was deemed as an independent predictor for poor sleep quality, while Mcsharry et al. [17] identified that both the increase in $\mathrm{BMI}$ and the decrease in $\mathrm{PaO}_{2}$ were considered independent predictors in those patients. On the other side, a group of studies had more or less different results; Chang et al. [25] proposed that CAT score was an independent factor for poor sleep quality in such patients; additionally, Ulfathinah et al. [37] demonstrated that patients with moderate to severe dyspnea were 2.28 times more likely to suffer from poor sleep quality.

Abd El-Fattah et al. [35] confirmed that there is strong association between poor sleep quality and physical limitation, COPD exacerbation, anxiety, depression, and poor health-related quality of life after using a group of subjective questionnaires for its assessment, and lastly, Shah et al. [38] noticed that presence of restless legs and obstructive sleep apnea symptoms, waist circumference, predicted diffusion capacity, and HADS anxiety and depression scores were identified as independent predictors of poor sleep quality.

This study had the following limitations. First, not all precipitating factors involved in disturbed sleep quality were evaluated (e.g., depression and anxiety). Second, small number of studied patients. Third, Pittsburgh Sleep Quality Index (PSQI) was not used in this study which is more sensitive in evaluating sleep quality.

Finally, we recommend involving sleep quality assessment in the risk categorization and management of different stages of stable COPD patients. Also, further studies were suggested to find out the impact of depression, anxiety, and comorbidities on sleep quality in COPD patients and their effect on quality of life.

\section{Conclusions}

Abnormal sleep quality is common in COPD patients with different grades of severity mostly in moderate and severe cases. Obstructive sleep apnea is the most frequent sleep-related breathing disorders among COPD patients followed by nocturnal $\mathrm{O}_{2}$ desaturation, nocturnal hypoventilation, and central sleep apnea. Increased BMI \%, lower values of $\mathrm{PaO}_{2}$, higher Berlin scores, and lower FOSQ-10 scores are strong predictors of poor sleep quality among COPD patients.

\section{Abbreviations}

COPD: Chronic obstructive pulmonary disease; REM: Rapid eye movement; OSAHS: Obstructive sleep apnea hypopnea syndrome; OVS: Overlap syndrome; ESS: Epworth sleepiness scale; FOSQ-10 short version: Functional outcome of sleep questionnaire; CVA: Cerebrovascular accident; BMI: Body mass index; CSAHS: Central sleep apnea hypopnea syndrome; mMRC: Modified Medical Research Council dyspnea scale; PSG: Full-night polysomnographic sleep study; AHI: Apnea Hypopnea Index; FEV 1 : Forced 
expiratory volume at first second; $\mathrm{PaO}_{2}$ : Partial arterial oxygen pressure; $\mathrm{PaCO}_{2}$ : Partial arterial carbon dioxide pressure

\section{Acknowledgements \\ Not applicable.}

\section{Authors' contributions}

AG and ME participated in performing study design and coordination. DG and YA contributed in patient selection and acquisition, analysis, and interpretation of data. Preparation of the draft was carried out by DG. The manuscript was substantially revised by $A G, M E$, and DG. All contributing authors have read and approved the final manuscript file.

\section{Funding}

Not applicable.

\section{Availability of data and materials}

Data used are available from the corresponding author upon reasonable request.

\section{Ethics approval and consent to participate}

This study was approved by the Ethics Committee of Zagazig Faculty of Medicine. The committee's reference number is not applicable. An informed written consent was collected from all participants.

\section{Consent for publication}

Consent for publication was obtained from all contributors.

\section{Competing interests}

Not applicable.

\section{Author details}

${ }^{1}$ Chest Department, Faculty of Medicine, Zagazig University, Zagazig, Egypt

${ }^{2}$ Hehia Central Hospital, Hehia, Sharkia Governorate, Egypt.

Received: 14 June 2020 Accepted: 6 November 2020

Published online: 07 January 2021

\section{References}

1. NHLBI/WHO, Global Initiative for Chronic Obstructive Lung Disease (GOLD) Strategy for the diagnosis, management, and prevention of chronic obstructive pulmonary disease 2012.Available at:<http://www.goldcopd.com

2. Patrick R (2016) COPD's effect on sleep: COPD can affect healthy sleep, especially in those patients where COPD and obstructive sleep apnea occur together, a condition known as COPD-OSA overlap syndrome. RT Decision Makers Respiratory Care 29(5):18+

3. Khalil NS, Mostafa MF, Ahmad NY, El-sayedd AY (2019) Sleep quality among patients with chronic obstructive pulmonary disease at a university hospital in Egypt. Clin Pract 16(2):1085-1092

4. Budhiraja R, Siddiqi TA, Quan SF (2015) Sleep disorders in chronic obstructive pulmonary disease: etiology, impact, and management. J Clin Sleep Med 11(3):259-270

5. Viswanath A, Ramamurthy J, Dinesh SP, Srinivas A (2015) Obstructive sleep apnea: awakening the hidden truth. Niger J Clin Pract 18:1-7

6. Malhotra A, Schwartz AR, Schneider H, Owens RL, DeYoung P, Han MK et al (2018) Research priorities in pathophysiology for sleep-disordered breathing in patients with chronic obstructive pulmonary disease an official American Thoracic Society Research Statement. Am J Respir Crit Care Med 197(3):289-299

7. McNicholas WT (2017) COPD-OSA overlap syndrome evolving evidence regarding epidemiology, clinical consequences, and management. CHEST 152(6):1318-1326

8. Du W, Liu J, Zhou J, Ye D, OuYang Y, Deng Q (2018) Obstructive sleep apnea, COPD, the overlap syndrome, and mortality: results from the 20052008 National Health and Nutrition Examination Survey. INT J CHRONIC OBSTR 13:665-674

9. Global Initiative for Chronic Obstructive Lung Disease (GOLD) for the diagnosis, management strategy and prevention of chronic obstructive lung disease (updated 2016) [homepage on the Internet]. Available at: http:// www.goldcopd.com. Accessed 18 Dec 2016.
10. Young T, Palta M, Dempsey JA, Skatrud J, Weber S, Badr S (1993) The occurrence of sleep disordered breathing among middle-aged adults. N Engl J Med 328(17):1230-1235

11. Thurtell MJ, Bruce BB, Rye DB, Newman NJ, Biousse V (2011) The Berlin questionnaire screens for obstructive sleep apnea in idiopathic intracranial hypertension. J Neuro Ophthalmol 31(4):316-319

12. Chasens ER, Ratcliffe SJ, Weaver TE (2009) Development of the FOSQ-10: a short version of the functional outcomes of sleep questionnaire. Sleep 32: 915-924

13. Young T, Peppard PE, Taheri S (2005) Excess weight and sleep-disordered breathing. J Appl Physiol 99(4):1592-1599

14. Jones PW, Harding G, Berry P, Wiklund I, Chen WH, Leidy NK (2009) Development and first validation of the COPD assessment test. Eur Respir J 34(3):648-654

15. Tsara V, Amfilochiou A, Papagrigorakis MJ, Georgopoulos D, Liolios E (2009) Guidelines for diagnosis and treatment of sleep-related breathing disorders in adults and children. Definition and classification of sleep related breathing disorders in adults: different types and indications for sleep studies (Part 1). Hippokratia 13(3):187-191

16. Landry GJ, Best JR, Liu-Ambrose T (2015) Measuring sleep quality in older adults: a comparison using subjective and objective methods. Front Aging Neurosci 7:166

17. Mcsharry DG, Ryan S, Calverley P, Edwards JC, McNicholas WT (2012) Sleep quality in chronic obstructive pulmonary disease. Respirology 17(7):11191124

18. Akerstedt T, Schwarz J, Gruber G, Lindberg E, Theorell-Haglöw J (2016) The relation between polysomnography and subjective sleep and its dependence on age-poor sleep may become good sleep. J Sleep Res 25(5): 565-570

19. Cohrs S, Rodenbeck A, Riemann D, Szagun B, Jaehne A, Brinkmeyer J et al (2014) Impaired sleep quality and sleep duration in smokers-results from the German multicenter study on nicotine dependence. Addict Biol 19(3): 486-496

20. Liao Y, Xie L, Chen X, Kelly BC, Qi C, Pan C et al (2019) Sleep quality in cigarette smokers and nonsmokers: findings from the general population in central China. BMC Public Health 19:808-817

21. Miller L, Clavé $P$, Farré R, Lecea B, Ruggieri MR, Ouyang A et al (2013) Physiology of the upper segment, body, and lower segment of the esophagus. Ann N Y Acad Sci 1300:261-277

22. Krachman SL, Chatila W, Martin U, Permut I, D'Alonzo G, Gaughan J et al (2011) Physiologic correlates of sleep quality in severe emphysema. COPD : Journal of Chronic Obstructive Pulmonary Disease 8(3):182-188

23. Azuma M, Chin K, Yoshimura C, Takegami M, Takahashi K, Sumi K et al (2014) Associations among chronic obstructive pulmonary disease and sleep-disordered breathing in an urban male working population in Japan. Respiration 88:234-243

24. Adetiloye AO, Erhabor GE, Obseki DO, Adewole OO, Awopeju OF (2018) Prevalence of sleep impairment and assessment of sleep patterns using Pittsburgh Sleep Quality Index in patients with chronic obstructive pulmonary disease. Ann Med Health Sci Res. 8:304-309

25. Chang $\mathrm{CH}$, Chuang LP, Lin SW, Lee CS, Tsai YH, Wei YF et al (2016) Factors responsible for poor sleep quality in patients with chronic obstructive pulmonary disease. BMC Pulmonary Medicine 16:118

26. Vogelmeier CF, Criner GJ, Martinez FJ, Anzueto A, Barnes PJ, Bourbeau J et al (2017) Global strategy for the diagnosis, management, and prevention of chronic obstructive lung disease. 2017 Report. GOLD Executive Summary. American Journal of Respiratory and. Critical Care Medicine. 195:5

27. Krieger AC, Patel N, Green D, Modersitzki F, Belitskaya-Levy I, Lorenzo A et al (2007) Respiratory disturbance during sleep in COPD patients without daytime hypoxaemia. Int J Chron Obstruct Pulmon Dis 2(4):609-615

28. Sanders $M H$, Newman $A B$, Haggerty $C L$, Redline $S$, Lebowitz M, Samet J et a (2003) Sleep and sleep-disordered breathing in adults with predominantly mild obstructive airway disease. Am J Respir Crit Care Med 167(1):7-14

29. Abdel ML (2007) Nocturnal oxygen desaturation in COPD patients with or without obstructive sleep apnea hypopnea syndrome. MSc Thesis, Chest Department, Mansoura Faculty of Medicine

30. Povitz M, James MT, Pendharkar SR, Raneri J, Hanly PJ, Tsai WH (2015) Prevalence of sleep-disordered breathing in obese patients with chronic hypoxemia. A cross-sectional study. Ann Am Thorac Soc 12(6):921-927

31. Dhingani D, Copur AS, Khatri V, Fulambarker A (2016) Role of nocturnal oxygen desaturation for the diagnosis of coexistent obstructive sleep apnea 
in patients with COPD. American Thoracic Society 2016 International Conference. B63. My way: OSA Outpatient Models of Care: A4180.

32. McNicholas WT, Verbraecken J, Marin JM (2013) Sleep disorders in COPD: the forgotten dimension. Eur Respir Rev 22:365-375

33. Chen R, Tian JW, Zhou LQ, Chen X (2015) The relationship between sleep quality and functional exercise capacity in COPD. CLIN RESPIR J 10:477-485

34. In E, Turgut T, Özdemir C (2016) Impact of restless legs syndrome on the sleep quality in chronic obstructive pulmonary disease. Eurasian $\mathrm{J}$. Pulmonol. 18:18-23

35. Abd El-Fattah MT, Abd El-Aziz AO, Abd El-Gahny EA, Khedr MHS (2018) Sleep quality in COPD patients; incidence and predictors of poor quality Med. J. Cairo Univ. 86(1):107-115

36. Scharf SM, Maimon N, Simon-Tuval T, Bernhard-Scharf BJ, Reuveni H, TaraSiuk A (2011) Sleep quality predicts quality of life in chronic obstructive pulmonary disease. Int. J. Chron. Obstruct. Pulmon. Dis. 6:1-12

37. Ulfathinah A, Rachmi SF, Indracahyani A (2019) Characteristics affecting sleep quality of COPD patients. Enferm Clin. 29(S2):30-35

38. Shah A, Ayas N, Tan WC, Malhotra A, Kimoff J, Kaminska M et al (2020) Sleep quality and nocturnal symptoms in a community-based COPD cohort. COPD 17(1):40-48

\section{Publisher's Note}

Springer Nature remains neutral with regard to jurisdictional claims in published maps and institutional affiliations.

\section{Submit your manuscript to a SpringerOpen ${ }^{\circ}$ journal and benefit from:}

- Convenient online submission

- Rigorous peer review

- Open access: articles freely available online

- High visibility within the field

- Retaining the copyright to your article 